\title{
Health and Wellbeing Networks for Older People: A Scoping Review for Future Research
}

\section{Meads G* and Lees AL}

Department of Health Sciences, University of Winchester, UK

*Corresponding author: Geoffrey Meads, Faculty of Health, University of Winchester, UK, Email: Geoffrey.Meads@winchester.ac.uk

\section{Research Article}

Volume 2 Issue 3

Received Date: May 22, 2019

Published Date: June 26, 2019

DOI: $10.23880 /$ jqhe- 16000127

\section{Abstract}

The context of escalating need for government funded health care services encourages policymakers to develop new enterprises which can relieve demand for statutory services. This concept based article reports a scoping review designed to identify priorities for a research agenda of organisational studies which can examine these enterprises, and their emerging relational networks, within an expanding health and wellbeing sector. The review includes a thematic analysis in which transferable learning from recent ethnographic studies in Australia and the United Kingdom is presented. This is supported by lessons drawn from expert subject advice in follow up research projects and applications. The two countries were originally selected because of their rapid new development of wellbeing services. Overall findings point to distinct types of relational network, and informal leaderships emerging to facilitate wider access to social enterprises and informal health and wellbeing services. As 'actor networks' these are classified by their material features. Spiritual leaders and resources are shown to contribute significantly to these networks, which also incorporate sports, arts and therapeutic practices. With public health and social care strategically aligned in many market based systems globally, the review concludes that research on alternative network development processes is required for local authorities with community development responsibilities. Overlapping relationships between alternative networks may offer the prospect of more holistic approaches to public health and health care quality that reduce pressures on government funded interventions.

Keywords: Wellbeing; Network; Relational; Spiritual; Social Enterprise; Scoping Review

Abbreviations: UK: United Kingdom; EBM: Evidence Based Medicine; NHS: National Health Service; WSE: Winchester Social Enterprises.

\section{Introduction}

This article adopts an international perspective for a scoping review in which it identifies indicative findings, with potentially wider significance, from two local sites where the innovative growth of new wellbeing services has been particularly in evidence. The article starts with a summary of underpinning theory, and then describes relevant policy and organizational developments in health and social care systems. As a specific focus the enhanced contemporary roles of spiritual agency and religious interest are explained, and detailed classifications of the identified alternative relational wellbeing networks 


\section{Journal of Quality in Health Care \& Economics}

charted in tabular form. A secondary data analysis from the ethnographic case studies, supported by expert subject advice, is then structured around three broad themes. These inform the concluding recommendations for future research.

\section{Context}

This article is underpinned by a 'dynamic equilibrium' theory that views wellbeing as being established when individuals or communities 'have the (combined) psychological, social and physical sources to meet a particular psychological, social and/or physical challenge' [1]. This theory originated almost forty years ago [2]; and over time it has helped pave the way for a holistic approach, in both health care and other service sectors, which has helped to break down barriers between previously separate notions of economic, structural and, in particular, psychological wellbeing. The result now is a series of broad based domains. These are far removed from earlier one dimensional ideas of wellbeing as, for example, simply happiness, an extended lifecycle, or recovery from adverse events [2-4].

Since 2010 in the United Kingdom (UK), the national government has itself adopted domains to measure wellbeing levels. One consequence of its 'What Works for Wellbeing' policy initiative is the creation of space for faith oriented social enterprises to enter the sector [5]. This in turn has helped to facilitate the inclusion of the spiritual dimension into descriptions and definitions of wellbeing.

These developments are especially pertinent for older people, for whom spiritual wellbeing often has an enhanced significance as physical prowess declines [6,7]. Recent studies have pointed to the particular benefits of informal networks for older people's health, especially in respect of conditions which are susceptible to improvement through enhanced relationships, such as depression [8,9]. Historically, the starting points for enquiry into informal networks of interpersonal relationships have been first, the needs of the formal system for back-up support, often in the post-operative phase of treatment [10]; and secondly environmental and cultural fit [11]. Networks have overwhelmingly been understood as emanating from the extended family or local neighbourhood. These both frame standard classifications, and the frequently cited and used 'Wenger' network assessment tools [12]. As a result findings typically relate to the impact of different 'clans', race, and gender, with for example, older men often found to experience more severe levels of loneliness linked to lower competencies in social network development $[13,14]$.

Not surprisingly, however, such findings now seem to belong to a different era and contemporary research has not yet caught up with the rapid expansion in frontline wellbeing service outlets and social enterprises often led by spiritual agencies. The 'scoping' review described here seeks to start to address this knowledge gap. Our aim is to offer an empirically based research agenda for future studies.

\section{Background}

Over the past twenty five years religion inspired relational thinking has made a series of important contributions to both policy and practice developments in health and social care. This has been true internationally, and is particularly apparent in the two countries that provide the principal secondary data for this article, the United Kingdom (UK) and Australia. Here, for example, spiritually motivated policy think tanks such as The Jubilee Centre and Revenuer have been closely associated with the creation of relational social justice and interprofessional governance models [15-17].

In addition there is common ground between Australia and the UK in their successive policies for decentralization to primary and community care settings. These have led to the devolution of resources for the contracting and commissioning of health care by local practices. In global terms this has occurred particularly quickly, and has been aligned with a parallel rapid expansion of independent sector wellbeing services. This 'pioneer' status underpins our site selection for this study. It is reflected in various 'Liveability' awards for the cities of Melbourne and Winchester, and exemplified by provincial level performance indicators for wellbeing performance [18]. In the cases of both the UK and Australia, the intellectual sources for such new organisations as primary care trusts and primary healthcare networks have included agencies with religious foundations, and authors whose starting point for promoting relational thinking is, at least in part, spiritual [19-23]. The relational proximity health care model, for example, from The Jubilee Centre at Cambridge in the UK, was originally derived from Old Testament study [24].

This stream of social thought in health care has also entered mainstream service delivery at the same time as health services have also been strongly influenced, in their pursuit of both improved quality and economic value, by the more empirical and secular sources of such 


\section{Journal of Quality in Health Care \& Economics}

as systemic family therapy and evidence based medicine (EBM) $[25,26]$. Accordingly, the structured formulae of Evidence Based Medicine (EBM) protocols, National Health Service (NHS) performance audits in the UK, and Canberra's Commonwealth health promotion programmes have been in contrast, but in parallel with the looser network initiatives for community development of such as the City Bond and Good Neighbour Support Schemes associated with the recent religiously motivated relational movements.

As a result of this coincidence of timing the social thought of Relationism can be understood in the literature to counter-balance the more calculative ideas which are employed by policy makers to constrain the use of public expenditure in both health and social care $[27,28]$. Backed by a hierarchy of research evidence which begins with randomised or cluster control trials, these last ideas are closely associated with service rationing, demand management and the clinical sciences. Internationally, they fit well with an economic environment still recovering from the financial market crisis of a decade ago.

In both the UK and Australia, the sense of mid-term economic pressure is made more acute by ageing demographic profiles and significant shifts towards cost sharing and co-payments. For both countries these shifts include more income generating local social enterprise developments in a burgeoning 'Third' care sector that includes multiple faith related agencies. This sector comprises independent organisations which are in neither state nor personal ownership. There is now a growing literature assessing how these seek to operate as business ventures located between exclusively funded public or private services. UK commentators term these as 'place-based' rather than 'person centred'-community development and health initiatives $[29,30]$.

As an important element in this independent sector growth faith oriented agencies are now major contributors to these modern organisational development trends. In relation to this present study, for example, by the end of 2020, the diocesan Winchester Social Enterprises agency (WSE) of the Anglican Communion proposes to take responsibility across a county area of 1.7 million people for around $60 \%$ of children under-5's day care provision in a 'Launchpad' initiative. For such services as food banks and street and station pastors it is churches of different denominations that already provide the majority of capital and human resources. WSE and 'Launchpad' are the flagship of the Winchester Cathedral's 2017-2020 Diocesan Mission Action Plan for 'Social
Transformation' [31]. It is one of no fewer than 70000 social enterprises operating nationwide [32].

Australia too has a history of ground breaking developments in non-governmental organisations and charitable activities which cross denominations. The Australian sites referred to in this article are located in an area of Melbourne denominationally distinctive for its many Uniting Churches. For over forty years these have brought together under one roof, and into one community of (Protestant) faith, Methodists, Congregationalists and Presbyterians; (plus a few itinerant Anglicans). In both our South of England and Victoria locations religious interest stems from a 'missional' motif. The objective is expanded church membership through an enhanced approach to outreach, which takes advantage of growing public interest in different forms of both spirituality and their associated health and wellbeing services. Empirically based research may be regarded as one source of transferable learning in comparable settings to support this goal.

In both Australia and the UK, both public health and social care have now become the responsibility of local municipal authorities, and are no longer directly accountable at central government level to the Commonwealth or the NHS. Conceptually the new organisational connectivity is designed to reflect the enhanced value of Integration. Historically Integration was a simple service principle applied, for example, 'vertically' to relationships between general practitioners in primary health care and specialist consultants in hospital based acute care. Now Integration is a continentwide value for community health development, at the heart of both the European Union and the Australian Confederation, into which faith agencies are increasingly drawn. For faith based agencies a significantly changing context is clearly emerging for the 'transformative' social action to which they aspire.

As a result 'best value' health service provision is increasingly located in the contemporary context of integrated care. This is also the case for public health strategies where networks are also increasingly understood to be relational and multi-faceted. Integration applies now to aligning physical and mental health with social and spiritual frameworks just as much as in the past it was a label used to describe, more narrowly, government funded social work and health care professional combinations, or the internal elements of just one element in such terms as 'spiritual integration' $[16,33]$. 


\section{Journal of Quality in Health Care \& Economics}

This expansion of meaning is most pertinent for the older generation, where the pressures to access preventive and promotional resources for health care and wellbeing in community settings are the most insistent. Institutional care is expensive, restricted and often restrictive, and still mostly secular. Modern relational networks for seniors seem to offer new opportunities, and hope. And on both counts religion may be understood to score highly. Understanding how faith oriented agencies behave in this changing context is important both for these agencies and their clients, but also too for the future of those persons working in social and spiritual service settings. In these settings it is clear that the risks as well as the opportunities arising from new relational networks are yet to be fully recognised.

\section{Methodology}

\section{Objectives}

Our overall purpose is to gain a sufficient understanding of how relational health and wellbeing networks develop, (particularly for seniors) in order that a legitimate empirical basis exists for a future research agenda to be defined. In this article the research questions articulated follow from 'proof of concept' first being established in respect of the relational networks. The research agenda may then, for example, be used by such as governmental strategy units, a diocesan study group, an embryonic social enterprise or, a social sciences research team. The supplementary target of the project is to provide transferable learning for faith related agencies, in particular, as they look to extend their social action roles and responsibilities.

\section{Approach}

In support of these goals a two year scoping review was undertaken in 2017-18 employing secondary data capture and analysis as its approach. This approach was shaped by notions of actor networks, in which sets of associations are defined through identifying and grouping specific 'materials' of 'social life' $[34,35]$. The data was derived from a series of previously reported ethnographic case studies focussing on governance arrangements in UK and Australian social enterprises [36,37]. This research employed a cascade approach, participant observation and involved site visits and interviews $(n=37)$ at a convenience sample of 16 local wellbeing practices. The secondary data analysis was undertaken in collaboration with 12 virtual advisory group members drawn from and nominated by the Universities of Winchester and Monash which sponsored the original primary research. For this purpose the data was organised using the five headings of:
Aims, Scale, Activities, Connections and Ethos. As a broad based comprehensive checklist regularly employed in community capacity building [38], these headings were selected to support our underpinning theoretical concept of the dynamic equilibrium for wellbeing. Advisory group members recommended additional literature searches and served as sounding boards for testing and validating emergent themes and categories.

\section{Analysis}

Individual advisory group members drew on their particular expertise and experience to assist in the development of the two tabular classifications set out below. Their contributions to the first interpretative factor analysis between March and July 2017, enabled a simple typology of relational networks to be defined [39]. This was principally based on the headings of 'Aims', 'Activity' and 'Connections'. A second stage of analysis was based on aggregating recurrent factors in relation to first: network development processes; and secondly: actual or asserted impacts. Data gathered under the headings of 'Scale' and 'Ethos' were included. Particular attention was paid to the role of spiritual agencies and religious leaderships; especially with and for older people. Finally, the analysis culminated in the researchers' reaching consensus on a critical overarching question for the future research agenda, as follows:

'How do informal network relationships develop both for, and by older people, and how can these effectively promote a comprehensive sense of wellbeing?'

\section{Results}

\section{Categories}

The findings from the secondary data analysis were twofold. The first is the novel classification of relational networks and their typical characteristics. These highlight, in particular, emerging modes of informal leadership and their knowledge bases. The second finding is a set of themes which served as the basis for formulating a set of viable and specific future research questions.

Table1 below separates relational networks conceptually on the basis of their principal focus for health and wellbeing: physical, mental, social and spiritual. Typical examples of observed activities and nomenclatures are provided as illustrations. More significantly, examples are also given of the kinds of roles that exercise leadership through developing and sustaining the networks and their supportive health care resources. These vary with the different principal focus. 


\section{Journal of Quality in Health Care \& Economics}

For instance, a life coach may create links and recommendations for a range of gyms, pools, running events, nutritional aids, podiatrists and personal trainers; while the counsellor's leadership stems from being a 'hub' for such as mindfulness sessions, information on retreat centres, cognitive therapies and reflective practices. In each type of network a 'trusted' knowledge source is often quoted, including, in some instances, alternative appropriate religious texts for spiritual networks. Of course each network is not completely discrete. Memberships and activities overlap, and in some cases different leaders re-inforce each other through their shared connections and 'referrals' to one another. The last may engender some competition for business dividends, as in the case of the 'healthy' eating places which may function as network 'hosts' (Table 1).

\begin{tabular}{|c|c|c|c|c|}
\hline $\begin{array}{c}\text { Wellbeing } \\
\text { focus: }\end{array}$ & Activity focus: & $\begin{array}{c}\text { Leadership Hubs } \\
\text { (e.g.s): }\end{array}$ & $\begin{array}{c}\text { Knowledge base } \\
\text { sources: }\end{array}$ & $\begin{array}{c}\text { UK and Australia Networks (anon.): } \\
\text { Hampshire/Victoria }\end{array}$ \\
\hline Physical & Sports and exercise & Life coaches & Physiology & Seniors sporting 'Academies' \\
\hline Mental & Arts and creativity & Counsellor & Psychology & Community choir/ Revival group \\
\hline Social & Meetings and mobility & $\begin{array}{c}\text { Community } \\
\text { organiser }\end{array}$ & Social Work & $\begin{array}{c}\text { Good Neighbours Support/Rotational } \\
\text { Circles }\end{array}$ \\
\hline Spiritual & $\begin{array}{c}\text { Reflection and } \\
\text { fellowship }\end{array}$ & Pastoral guru & Religion(s) & 'Explorers' evening get-togethers \\
\hline
\end{tabular}

Table 1: Classification of relational networks for health and wellbeing.

The other classification is that of the specific 'materials' which characterise and comprise each type of network. The lists for each in Table 2 below are derived from being repeatedly cited in observations, respondent interviews and expert advisor communications. For each type, as clusters, they permitted the researchers to describe an overarching network ethos: from individual through intergayen and interpersonal to metaphysical as the focus moves from physical through mental and social to spiritual wellbeing. Again there are overlaps and duplication, but also clear distinctions between networks. Moreover, their inter-relationships could also, it seems, be considered in terms of status pecking orders for influence and authority; both short term and sustained. Understanding this led to the further analysis of emergent themes. These are discussed below.

\begin{tabular}{|c|c|c|c|c|c|}
\hline Jetwork & Aims & Scale & Activities & Connections & Ethos \\
\hline Physical & $\begin{array}{c}\text { Enhanced sports performance, } \\
\text { exercise routine and targets , } \\
\text { egalitarian approach across } \\
\text { generations and gender }\end{array}$ & $\begin{array}{c}\text { Daily schedules, } \\
\text { Kettlebells, early } \\
\text { morning warm ups and } \\
\text { regular work outs, } \\
\text { standard pool and sea } \\
\text { usage } \\
\end{array}$ & \begin{tabular}{|} 
Cycling routes, Jogging \\
and power walking, \\
flexibility sessions, \\
Pilates
\end{tabular} & $\begin{array}{c}\text { Personal trainers, Exercise } \\
\text { Physiologists, Strava, Muscular } \\
\text { Skeletal practitioners, Physios } \\
\text { first aid and OTs, gym suites }\end{array}$ & Individual \\
\hline Mental & $\begin{array}{c}\text { Safety and support, periods of } \\
\text { respite and refuge, healing and } \\
\text { awareness of Nature, recovery } \\
\text { and self-awareness }\end{array}$ & \begin{tabular}{|c|} 
Timetabled classes and \\
clubs, protected spaces, \\
confidential exchanges \\
and safety valves
\end{tabular} & \begin{tabular}{|} 
Music and art therapies, \\
crafts, Yoga, \\
environmental \\
protection, meditation \\
\end{tabular} & \begin{tabular}{|c|} 
Cognitive Behaviour and other \\
Psychologists, Verse, colour \\
charts, Celtic traditions, choirs, \\
galleries, healthy eater venues
\end{tabular} & Inte \\
\hline Social & $\begin{array}{l}\text { Befriending, neighbourliness, } \\
\text { enhanced mobility, } \\
\text { involvement, value for money. }\end{array}$ & $\begin{array}{c}\text { Monthly cycles, cultural } \\
\text { calendars, flower shows } \\
\text { and exhibitions, }\end{array}$ & $\begin{array}{c}\text { Shared transport } \\
\text { schemes, regular } \\
\text { hospitality events, } \\
\text { affiliated societies and } \\
\text { associations } \\
\end{array}$ & $\begin{array}{l}\text { Book and theatre groups, coffee } \\
\text { houses, volunteer training, }\end{array}$ & $\begin{array}{l}\text { Inter } \\
\text { personal }\end{array}$ \\
\hline Spiritual & $\begin{array}{c}\text { 'Missional' fellowship, life cycle } \\
\text { awareness, self- exploration, } \\
\text { palliative and restorative }\end{array}$ & $\begin{array}{c}\text { Seasonal observances, } \\
\text { religious occasions, } \\
\text { ongoing witness, truth } \\
\text { seeking witness and } \\
\text { narratives }\end{array}$ & \begin{tabular}{|c|} 
Scriptural texts, divine \\
sources, Contemplative \\
Christianity quiet times, \\
soulfulness and \\
mindfulness, retreats
\end{tabular} & $\begin{array}{c}\text { Key writers and speakers, } \\
\text { churches, shrines and house } \\
\text { groups, }\end{array}$ & $\begin{array}{c}\text { Meta } \\
\text { physical }\end{array}$ \\
\hline
\end{tabular}

Table 2: The characteristics of health and wellbeing networks. 


\section{Journal of Quality in Health Care \& Economics}

\section{Themes}

The three themes were derived by our joint examination in depth of the original interviews and observational data to identify any critical discourses and events noted in the research. This examination was augmented by our exchanges with the project advisors. The data pointed to encounters and/or incidents on which a network's essential justification seemed to rely, and aggregating these enabled us to recognise the following themes. The thematic analysis was then augmented for each theme by topic based literature searches specifically in respect of health and health care.

\section{$>\quad$ One: Primacy of Spiritual Hubs}

This theme was sometimes implicit but articulated in interviews most clearly by two trained priests who saw themselves as sources and recipients of transferable learning. Their accounts, accordingly, are provided here to illustrate this first theme.

Both pastors are ecumenical rather than overtly evangelical in outlook; focusing on community wellbeing first and congregational needs next. Both espouse religious positions in which the spiritual and secular can be intertwined for 'the common good'. They each support numerous cross-agency initiatives which contribute to 'positive' responses arising from recent State sponsored policies in the UK and Australia designed to combat loneliness and social isolation in older people [40]. For these two spiritual leaders Wellbeing required functional levels of integration between relational networks, and as spiritual leaders that felt they were often best placed to promote the overlaps required between service inputs for this integration. The reasoning behind this judgement was that religious faith and spiritual health can be, and generally are understood, in health terms, to constitute the profound and most lasting dimension of authentic wellness. In short, the spiritual is understood to trump the physical, mental and social. Their view was that it goes deeper, and this perception was one shared by those both with and without a faith orientation.

\section{$>\quad$ Two: Bureaucratic Barriers}

This theme was a persistent feature of site interviews and the subsequent literature search. First, formal institutions and professions were regularly spoken of as significant obstacles to network development. This was especially pronounced at the UK sites. For example, at a seniors' network lunch in Winchester one attendee asserted:

'The NHS is really almost the problem. We only want to come to something if we know it has the official backing of the NHS; if we know one of theirs is supporting.'

The interviewees here preferred it when a medical consultant 'popped in' or a physiotherapist gave approval for a new exercise regime.

Similarly, the organiser of one of the local Good Neighbour Support Schemes in Hampshire asserted:

"The NHS and local councils just do not understand how to manage volunteers. They dump on us and then require forms to be filled out which require totally insensitive answers such as on missing family members and status. They act as if they are the sole sponsors.'

Another local leader of an informal social network in Winchester complained that 'past conditioning' by government funded authorities meant 'befriending is seen to mean buildings not networks, with separate formal responsibilities: specialist functions not collaborations or community locations' She concluded that this would only lead to 'stunted growth, and loads of misspent time and energy on capital rather than community developments.'

In Melbourne, one respondent associated this same perspective with issues of social class and inclusion. She suggested that in poorer areas bureaucratic Medicare terms and procedures blocked social network developments. The most dramatic expression of this sense of alienation from networks that could fall under the influence or control of formal institutions and professions also came in Melbourne. It took the form of a refusal by one exercise based network leader to take part in the research project. Here the proprietor summarily ended an interview when he realised the findings could potentially be made available for Medicare or a local authority council's use. For him emerging relational networks were in his words the 'only holy grail' to business success and genuine 'all round health care and wellbeing', and they should not be 'contaminated' by government funded public service agencies: 'they just get in the way'.

This first part of the theme in respect of institutional and professional obstacles, however, also indicated a second learned outcome in terms of opportunity: for incentivising alternative relational networks. This opportunity seems to fit with the changing role of local authorities in many Western democracies with managed health and social care market systems: as enablers and regulators of community health and wellbeing, and the informal and voluntary resources these systems require. In the municipal authorities of Melbourne the need to harness the positive resources of informal networks was 


\section{Journal of Quality in Health Care \& Economics}

being recognised and epitomised by the city's recently developed Wellbeing Audit Scales and Older Peoples' Quality Care Framework [41]. In Winchester the most obvious expression of this opportunity is the local authority's inter-agency Health and Wellbeing Board which seeks to promote joint health care and social service developments.

\section{$>\quad$ Three: Reciprocity}

The interviewee's simple comment above about bureaucracies 'getting in the way' was frequently echoed by those respondents who emphasised what they saw as the particular health dividend of emerging relational networks from spiritual sources. This was often equated with pastoral care. In this context, a main attraction of new health and wellbeing networks is that status is much less differentiated and equal. For example, the chairperson of a Christian charity dedicated to community development and social 'construction', emphasised the role of churches in 'stimulating and enabling' supportive relationships which are 'informal' and reciprocally rooted in the sharing of 'personal values'.

This understanding of the principle of reciprocity, as our third overall theme and the foundation of what one social enterprise leader called 'the best form of relational networks', was evident and explicit in the discourses of faith based social support schemes in both Australia and the UK. In the first, the regular re-use of redundant street corner church buildings for , typically, combinations of meditation, pilates, exercise circuits and fellowship, was identified as a new two way exchange between "health and leisure' that might be deliberately engineered by spiritual leaderships as a 'survival strategy'. A Melbourne interviewee stated that:

'The notion of healthy ageing depends on both evidence and illusion. So people can only think of this as 'the best of times' if the illusion is given some credence. This is where the religious agencies come in. They are really necessary to what feels like a modern hedonistic approach, which keeps these networks going.'

In this sense of a fair exchange he believed that 'priests and faith leaders are the ideal candidates to help pilot people through when the old system is seen to have failed'. Having to cope in times of increased drugs prescriptions and fewer government funded options he viewed pastors and the people as 'on a par with each other'. And he concluded: 'After all clergy are concerned with the last of all questions, when all the rest are resolved!'

In the UK similarly the practice of reciprocity has also been described as becoming increasingly 'dynamic'. For example, in Good Neighbour Support and Community Navigator scheme sites a 'coping' culture was observed of not distinguishing between volunteers and clients where they are viewed as equal participants and beneficiaries. The parity of one-to-one personal relationships was stressed by a number of interviews, with transport, for example, regarded as a means to an end not the end in itself and houses shared for hospitality purposes. At a local Winchester sports hub one interviewed manager spoke eloquently of how staff training is rooted in 'an absolute commitment to equality of attention' so that 'an older person's ambition must be treated as the same as a bright young person's prospects'. No discrimination at all was tolerated. Here, typically for a health and wellbeing relational network hub, on-site facilities functioned as venues for healthy eating, personal fitness assessments, and seniors' golfing and social groups.

\section{Discussion}

\section{Implications for Practice}

The example of reciprocity in action given in the preceding sentence in the UK still appears to be quite unusual. Its relative absence from inter-agency relations especially has been a major challenge for both practice and theory in health care, public health and social thought. Many UK interviewees highlighted the continuing separation of different networks while Australian respondents emphasized the cultural differences between multiple migrants as individuals. Their detachment from one another 'the walkers, theatre goers and songs of praise people never meet' said one of our respondents is now a basic premise for National Health Service (NHS) sponsored health promotion initiatives through Genie and similar Internet linked social network products in the UK [42].

In the UK the NHS itself has recently sought to address its historic tendency towards restrictive clinical specialisms through 'Vanguard' pilots of more integrated health care and social work services, frequently in extended general practice settings [43]. This shift to multidisciplinary working is already much more apparent in Melbourne where the greater diversity of wellbeing service delivery outlets has created what has been termed as 'the new primary health care' [37].

Of course, there are exceptions. In the Winchester area, the success of the new golf academy over 3000 members in a little over two years is closely associated with the presence of a healthy eating commercial kitchen next to the driving range. In Melbourne its closest counterpart already has a bigger offer. It is attached to a gym, a café, a 


\section{Journal of Quality in Health Care \& Economics}

pool, a barbecue, consulting rooms, cycle tracks, a counselling and therapy centre, and a Parkrun. For religious agencies food and communion go together. Nutrition is common ground for Wellbeing, whether spiritual, social, mental or physical. It is seen as the most accessible means of promoting integration. In Melbourne network integration and brunch breakfasts appear to combine. It is over this meal, after the early morning bike ride, jog or walk together, that network leaderships comes into effect. Recognising this some Anglican churches, for example, in the Brighton suburb of Melbourne, have created a breakfast bar alongside their car parks. Others like the Bay side Uniting Church here nominate favourite health eating outlets for regular fellowship gatherings. No matter what the basis for the network this is where the wellbeing connections are often being made, and this is where future promotional health care resources may need to coalesce in a 'strengths based approach'.

From our research observations we saw network patterns emerging of sequences and linkages for health and wellbeing with new social enterprises as key contributors For example, a personal trainer refers clients on for sports massage and my therapy, with the 'scientific' backing of a host exercise physiologist; while the naturopathy alternative therapist provides the contact details for rural escapes, herbal remedies and folk concerts; backed by 'evidence' from environmental advocacy research institutes; and the music therapist draws on universities' clinical trials to link in with a range of creative artists addressing conditions that range from pain management to anxiety and stress. In each case there is food for social thought in health care, in the sense that the networks have an overriding philosophy of wellbeing and personal contact points which revolve around eating places.

Every network we identified also claimed an evidential base augmented by a sense of 'soulful' (or equivalent) experience. While this is most apparent in those emanating from church based hubs, it is also a key element elsewhere through such as the inclusion of for instance, yoga, nutritional therapy and graduated levels of nature trails in these different relational networks. For health care as for social work - there are clear implications in terms of utilising community assets in more radical approaches towards sources of support previously considered out-of-bounds [44].

\section{Learning Points}

A cultural shift is indicated for professions. In the UK, a window of opportunity exists within the framework of the
Care Act 2014, which promotes individual health and wellbeing in the broadest context and explicitly values older people as 'individual active citizens' [45]. For this value to be really enacted in health care delivery adult safeguarding is now critically important. On account of dementia, disability and other frailties, it will not be enough for informal networks simply to develop in an ad hoc fashion. For seriously disadvantaged seniors, health and social care professionals will need to consider, and revive, community work approaches such as neighbourho od profiling - in conjunction with more familiar clinical and casework models of intervention [46].

This can require a fundamental shift in the profession al/ service user relationship to one of building on the capacities of individuals, informal networks and the social capital of a much wider range of localities and distant sites in support of vulnerable and isolated individuals. By engaging with older people across tribal and traditional divides, facilitating integrated health and wellbeing network approaches can be regarded as 'safeguarding' the individual from risks of isolation.

Past studies have mostly focused just on the separate components of networks rather than their overall development and holistic health impacts. These have included such as the use of telephones, other health promotion aids, ethnic characteristics, and the Internet [47-49]. Understanding points of entry to networks; the risks, and the barriers and the prospective beneficiaries of relational intermediaries, is important [32]. So too are the potential contributions to meeting individual public health targets, such as the prevention of depression, falls and dementia [50]. This study has now also pointed to potential benefits to be derived for health care from the integration of relational wellbeing networks.

In short the learning from this study points to a need for radical changes in professional practice in which the boundaries and status differences between informal and formal service sectors are much less relevant, and applicable [51-53].

\section{Conclusion}

The evidence from this project helps to confirm not just the rapid increase in the relational health and wellbeing networks, but their expanding scale and sophistication, especially for older people. It highlights the mutually re-enforcing nature of these networks with emergent social enterprises and health care interventions from the independent sector [54-56]. Issues of integration are identified as a key future challenge for practice and policy, especially for those spiritual agencies committed 


\section{Journal of Quality in Health Care \& Economics}

to social action. These issues are understood to apply equally to those within voluntary and private enterprises as to those seeking to effectively combine formal health care with informal resources.

\section{Future Research Recommendations}

The first goal of the present study was to gain a level of subject understanding which would enable there to be the basis for future transferable leaning through a defined future research agenda. As a 'scoping' review for this purpose, using the headings of our analytical structure, five research questions have been defined by the researchers, and prioritised in conjunction with the project advisors. They are as follows:

- Activity: How can boundary functions between formal organizations and faith based social enterprises, be developed to support of older peoples' own relational wellbeing networks to promote healthcare?.

- Scale: Which organizational developments and strategies contribute most effectively to both ecumenical and health care work value?.

- Connections: Which interfaces between different relational networks of older people provide economically productive opportunities for integrating informally accessed health and wellbeing services?

- Ethos: What are the methodological implications for future research of the need to evaluate and measure the effectiveness of alternative relational networks, particularly for older people's health and wellbeing?

- Aims: How effective is health care practice in delivering better outcomes for older people through accessing new community resources, including those which emanate from different religious values based population groupings and spiritual agencies?

This is a substantial agenda for future research. Its potential learning outcomes are not just for those with managerial roles in such as diocesan churches and faith oriented social enterprises, but most obviously for strategic planners in health care institutions and municipalities. Having sought to help establish proof of concept through its relational network typology a key message from this study is also finally, that spiritual agency leadership can be an increasingly decisive factor in the future development of more integrated wellbeing networks. There may be significant benefits for the quality and value of health care practice as a result.

\section{Acknowledgements}

The authors would like to thank the Revs. David Williams, Bishop of Basingstoke, Kim Cain, Vicar of
Bayside Uniting Church, and Nick Ralph, Canon of Portsmouth Cathedral for their important contributions to the work described in this article.

\section{References}

1. Dodge R, Daly A, Huyton J, Sanders L (2012) The challenge of defining wellbeing. International journal of Wellbeing 2(3): 222-235.

2. Headley B, Wearing A (1989) Personality, life events and subjective wellbeing. Towards a dynamic equilibrium model. J Personal Soc Psychol 57(4): 731739.

3. Beaumont J (2001) Measuring national wellbeingdiscussion paper on domains and measures. Newport, ONS USA.

4. Goodman L, Fels Smyth K, Glenn C (2006) The Full Frame approach a new response to marginalized women left behind by specialized services. Am J Orthop 76(4): 489-502.

5. Letwin O, Swinson J (2014) New What Works Centre for Wellbeing. GOV. UK, Cabinet Office, London, UK.

6. MacKinlay E (2001) The spiritual dimension of ageing. Jessica Kingsley London.

7. Hennessey C (2004) Growing older: quality of life in old age. Maidenhead, Open University Press, UK.

8. Litwin H, Shiovitz-Ezra S (2006) Network type and mortality risk in later life. The Gerontologist 46(6): 735-743.

9. Duner A, Nordstrom M (2007) The roles and functions of the informal support networks of older people who receive formal support. Ageing and Society 27(1): 67-85.

10. Fraser SN, Rodgers WM (2009) Influences of upstream social factors on downstream perceptions of social support in cardiac rehabilitation. J App Soc Psychol 39(7): 1739-1761.

11. Wentowski G J (1981) Reciprocity and the coping strategies of older people: Cultural dimensions of network building. The Gerontologist 21(6): 600-609.

12. Wenger GC (1991) A network typology: from theory to practice. J Age Stud 5(2): 147-162. 


\section{Journal of Quality in Health Care \& Economics}

13. Borys S, Periman D (1985) Gender differences in loneliness. Personality and Social Psychology Bulletin 11(1): 63-74.

14. Wheeler L, Reis H, Neziek J (1983) Loneliness, social interaction and sex roles. Journal of Personality and Social Psychology 45(4): 943-953.

15. Burnside J, Baker N (2003) Relational Justice: repairing the breach. Winchester, Waterside Press, UK.

16. Meads G, Ashcroft J (2006) The case for collaboration in health and social care. Oxford, Blackwells, UK.

17. Busby D (2015) Trust. North Tambourne, Christian Management Australia, Queensland.

18. Meads G, Lees A (2016) Wellbeing agencies in the High Street: the rebirth of primary health care? The Open Public Health Journal 9: 31-37.

19. Milburn A (2000) NHS Plan. Department of Health, London.

20. Denham J (2006) Building cohesive communities. The Home Office, London.

21. Dutton P (2014) Primary Health Networks to drive better primary health care. Ministry of Health: media release, Canberra.

22. Bindman A, Weiner J, Majeed A (2001) Primary Care Groups in the United Kingdom: quality and accountability. Health Affairs 20(3): 132-145.

23. Booth M, Hill G, Moore MJ, Dalla D, Moore MG, et al. (2006) The new Australian Primary Health Networks: how will they integrate public health and primary care? Public Health Research Practice 26(1): e2611603.

24. Schluter M, Lee D (1993) The R Factor. Hodder\& Stoughton, London.

25. Winek J (2010) Systemic family therapy: from theory to practice. Sage, Los Angeles, USA.

26. Muir Gray J (2001) Evidence-based healthcare: how to make health policy and management decisions. Churchill Livingstone, Edinburgh.

27. Tilly C (2002) Stories, identities and political change, pp: 288.
28. Depelteau F, Powell C (2002) Applying Relational Sociology: relations, networks and Society. Palgrave MacMillan, New York.

29. Henderson P, Summer S, Raj T (2004) Developing hea lthier communities. London: Health Development Agency. Post Modernity and Social Work. British Journal of Social Work 24: 513-532.

30. The Place-Based Commission (2016) Get well soon. Re imagining Place Based Health. New Local Government Network and Collaborate, London.

31. Diocese of Winchester (2016) Sharing God's life. Brand Creative, Winchester.

32. Ralph N (2015) Good Neighbour Support Scheme 2015 Impact Briefing. GNSS, Winchester Social Enterprises, Portsmouth, UK.

33. Ridings J (2015) The development of a concept map for understanding spiritual integration in evangelically based social service organizations. J Relig Spiritual Soc Work 34(4): 331-355.

34. Latour B (2005) Reassembling the social: an introduc tion to Actor Network theory. Clarendon Press, Oxford, pp: 1-66.

35. Hassard J, Law J (1999) Actor network theory and after. Blackwells Publishing, Oxford.

36. Meads G, Lees A, Tapson C (2016) Creational narratives for new housing communities: evidence synthesis. Housing, Care and Support 19(3/4): 1-9.

37. Meads G, Russell G, Lees A (2017) Community governance in primary health care: towards an Ideal Type. Int J Health Plan Manag 32(4): 554-574.

38. Skinner S, Wilson M (2002) Assessing community strengths. A practice handbook for planning capacity building. Community Development Foundation, London.

39. Bryman A (2012) Social research methods. Oxford University Press, Oxford, UK.

40. Spanswick E (2016) Older people living with loneliness as 'fear and taboo' prevents them from seeking help.

41. Symondson T, Georgalas A (2017) Single Aged Care Quality Framework. Victoria Healthcare Association, Melbourne. 


\section{Journal of Quality in Health Care \& Economics}

42. Kennedy A, Vassilev I, James E, Rogers A (2016) Implementing a social network intervention designed to enhance and diversify support for people with long-term conditions. A qualitative study. Implementation Science.

43. Jones S (2017) Top tips for spreading new care models across heath and care system. NHS Confederation, London.

44. Lavalette M (2011) Radical Social Work Today: social work at the crossroads, $1^{\text {st }}$ (Edn.), Bristol University Press, pp: 248.

45. Bartnik E (2008) Active citizenship and community engagement-Getting serious about more positive pathways to relationships and contribution. Intellectual Disability Australia 29(2): 3-7.

46. Barclay P (1982) Social workers, their role and tasks. Bedford Square Press, London.

47. Cattan M, White M, Bond J, Learmouth A (2005) Preventing social isolation and loneliness among older people: a systematic review of health promotion interventions. Ageing and Society 25(1): 41-67.

48. Cattan M, Kime N, Bagnall AM (2011) The use of telephone befriending in low level support for socially isolated older people an evaluation. Health and Social Care 19(2): 198-206.

49. Wharton R, de La Casas R (2016) What a difference faith makes. Network Control Project, London, pp: 133.
50. National Institute for Health Research (2015) Public Health Research Programme: outline proposal guidance. NIHR, London.

51. Furman LD, Benson PW, Grimwood C, Canda ER (2004) 'Religion and Spirituality in social work education and direct practice in the Millennium: A survey of UK social workers. British Journal of Social Work 34 (6): 767-792.

52. Furness S (2003) Religion, belief and culturally competent social work competent practice. Journal of Practice Teaching in Health and Social Care 15(1): 6174.

53. Gilligan P (2003) It isn't discussed. Religion, belief and practice teaching: Missing components of cultural competence in social work education. Journal of Practice Teaching in Health and Social Care 5 (1): 7595.

54. Gilligan P (2009) Considering religion and beliefs in child protection and safeguarding work: is any consensus emerging?. Child Abuse Review 18 (2): 94110.

55. National Evaluations Trials and Studies Coordinating Centre (NETSCC) (2016). Interventions in community organisations to improve health and wellbeing and reduce inequalities. Southampton, UK.

56. Sheppard M (2006) Social Work and Social Exclusion: The Idea of Practice. Aldershot: Ashgate. 